\title{
Examining the Association Between Mentalizing and Parental Mental Health in a Sample of Caregivers of Children with Asthma
}

Javier Malda Castillo ${ }^{1}$, Claire Browne ${ }^{2}$, and Guillermo Perez-Algorta ${ }^{3}$

${ }^{1}$ North West Boroughs NHS Foundation Trust, Halton Hospital, The Brooker Centre,

Runcorn, WA7 2DA, England. j.maldacastillo@,outlook.com

${ }^{2}$ Manchester University NHS Foundation Trust, Harrington Building, Paediatric

Psychosocial Services, M13 9WL, England. claire.browne@mft.nhs.uk

${ }^{3}$ Division of Health Research, Faculty of Health and Medicine, Lancaster University, Furness

College, Lancaster, LA14YG, England. perezalg@exchange.lancs.ac.uk

Corresponding author: Dr Javier Malda Castillo 


\begin{abstract}
Background: Caregivers of children with asthma are at higher risk of experiencing mental health difficulties and lower quality of life than caregivers of healthy children. Mentalizing is a psychological construct that defines the ability of understanding one's own and others' states of mind. Poor levels of mentalizing are strongly associated with a wide range of mental health difficulties such as depression, anxiety or emotional dysregulation. This crosssectional study is the first to examine the associations between mentalizing and mental health in a sample of caregivers of children with asthma. Method: Caregivers of children (mean age $=6.53, \mathrm{SD}=3.72$, ages 1 to 17 ) with asthma were recruited from social media support groups and the Asthma UK charity research bulletin. Participants completed self report measures of mentalizing, family functioning, mood and anxiety difficulties. Results: A total of 88 caregivers completed the full survey. Results indicated that poorer mentalizing capacity was significantly associated with poorer family functioning and increased mood and anxiety symptomatology. Poor mentalizing was significantly associated with increased levels of depression, hypomania and anxiety, explaining $16 \%$ of variance in depression and $10 \%$ of variance in anxiety. Family functioning was not a significant predictor after controlling for the effect of mentalizing. Conclusions: These findings suggest that mentalizing capacity might be a valued new treatment target to improve the mental health of caregivers of children with asthma. The results suggest that mentalizing could complement previously identified factors such as family functioning or asthma symptom severity in understanding caregivers' mental health. Further investigation into the role of mentalizing in the mental health of this population is warranted.
\end{abstract}

Key words: caregivers, asthma, children, mentalizing, mental health 


\section{Examining the Association Between Mentalizing and Parental Mental Health in a Sample of Caregivers of Children with Asthma}

Asthma is a common chronic disease characterised by inflammation of the air passages, associated with recurring symptoms such as wheezing, shortness of breath or difficulties in sleeping, among others (Global Initiative for Asthma, 2017). Asthma can have a significant impact on the family unit, particularly amongst caregivers (Easter, Sharp \& Hunt, 2015). The prevalence of childhood asthma in the UK is one of the highest worldwide (British Lung Foundation, 2016; Mallol et al., 2013; Mukherjee et al., 2014). Asthma has a negative impact in terms of negative economic effects on healthcare, early mortality and partial or permanent disability (Gupta, Sheikh, Strachan \& Anderson, 2004; Nunes, Pereira \& Morais-Almeida, 2017). In the UK, the treatment and management costs of the illness have been estimated to be as high as one billion pounds annually (Asthma UK, 2016; Mukherjee et al., 2014).

\section{Caregiving and Mental Health}

Coughing or difficulties with breathing are common symptoms of asthma attacks. These episodes can be particularly scary if a child experiences them and can color the experience of the illness as acute or dangerous, making asthma attacks different from other chronic illnesses (i.e. diabetes) where the symptoms may be less visible. The experience of lack of control when these symptoms occur, could increase the stress in the family unit and affect caregivers' mental health and morale. In a recent meta-analysis, Easter, Sharp and Hunt (2015) noted that caregivers of children with asthma reported higher prevalence of anxiety and depressive symptoms than caregivers of children without medical diagnoses. Several longitudinal and cross-sectional studies have identified significant factors that seem to contribute to mental health difficulties of caregivers of children with asthma, such as low socio-economic status (Wood et al., 2002), asthma symptom severity (Halterman et al., 2004) and impaired family functioning (Sato et al., 2013; Zhou et al., 2014). 
The relationship between caregiving, mental health and children's asthma symptom severity can be considered systemic and dynamic, with back and forth effects between caregivers and the child. A multitude of research has proposed that caregivers' depression may be a significant contributor to flare-ups of asthma symptoms in children (Leiferman, 2002; Shalowitz et al., 2006; Wood et al., 2018). For instance, recent research suggests that caregivers' depression can contribute to the severity of asthma symptoms through a complicated cascade effect that produces alterations in immune modulation and autonomic regulation (Wood et al., 2018). An example of this would be that managing asthma requires a complex set of skills including preventing and responding to symptoms, medication management and communication skills to deal with healthcare providers. The mental health of caregivers with asthma may have an impact of how able do caregivers feel to cope with these challenges therefore possibly leading to misinterpreting and underestimating child's symptoms which could in turn affect the severity of the asthma outcomes.

Given the high prevalence of depression and anxiety symptoms in caregivers of children with asthma, and the impact that this might have in children's health outcomes, understanding the factors that may be associated with the development of mental health issues in these caregivers is paramount. Mentalization, a construct widely researched as a predictor of mental health problems in different clinical populations (Brent et al., 2014; Kovacs, Teglas, \& Endress, 2010; Lemma, Target, \& Fonagy, 2011), has been overlooked in the asthma caregiving literature. This is noteworthy because mentalization is a key psychological construct in understanding parent-infant relationships.

\section{Mentalizing and Mental Health}

The conceptualisation of mentalization emerged over two decades ago in the context of understanding attachment interactions between parents and babies (Fonagy, Steele, Steele, Moran, \& Higgit, 1991). Fonagy (1989) first described it as 
an ability that allows awareness of one's own and others' mental states, which in turn facilitates the understanding of behaviours, intentions, thoughts and feelings. Arguably, mentalization and attachment are intertwined and cannot fully be separated. Effective mentalizing is therefore a key element of attachment interactions because it allows parents to develop alternative understandings of their children's needs, which in turn helps to provide them with attuned responses (Fonagy et al., 1991). Several studies have demonstrated that difficulties in mentalizing are associated with different psychological difficulties including psychosis (Kovacs, Teglas \& Endress, 2010), personality disorders (Bateman \& Fonagy, 2013), depression (Lemma, Target \& Fonagy, 2011) or anxiety, among others.

On the contrary, robust mentalizing is associated with secure attachment and resilient responses in the face of stress (Bateman \& Fonagy, 2013; Fonagy, Gergely, Jurist, \& Target, 2002; Luyten, Fonagy, Lowyck, \& Vermote, 2012). Given that caregiving for a child with a chronic illness like asthma would possibly increase levels of stress in caregivers and the family unit, deepening the understanding of the contribution of mentalizing seems relevant. Although research shows that mentalizing is an important ability for mental health in the general population, including parents and caregivers, papers published to date have not explored mentalization with respect to the mental health of caregivers of children with asthma.

\section{Current Study}

The currently available literature suggests that asthma is burdensome and that caregivers of children with asthma are at greater risk of experiencing several mental health difficulties than their peers with healthy children. The visible aspects of the symptoms and the acute nature of asthma attacks in vulnerable children can make this chronic illness particularly stressful for the family unit. 
This study is unique because it employs a sample of caregivers of children with asthma, attempting to clarify whether the relationship between parental mentalizing and mental health difficulties occurs for this population and if it does, to what magnitude after controlling for other potential predictors. The associations between competing factors such as income, family functioning, asthma symptom severity, mentalizing and parental mental health difficulties are complicated.

The aim of this paper is to to understand the possible significant associations of mentalizing with parental mood [including hypomanic symptoms as they are an understudied aspect of mood problems (Youngstron \& Perez Algorta, 2015 )] and anxiety, when also accounting for variables that have been previously reported to be significantly associated with caregivers' mental health such as income, family functioning and asthma symptom severity.

Although the directionality of the associations between these variables will be very challenging to establish with the current cross-sectional design, this paper will potentially pave the way for further research to deepen the understanding of the factors that are interconnected with the mental health of parents of children with asthma. Finally, this research hypothesised that greater mentalizing capacity would be significantly associated with reduced anxiety, depression and hypomanic symptoms even after accounting for competing factors previously identified by the literature. Furthermore, it hypothesized, that mentalizing would be the greatest contributor in explaining variance in models that also included income, asthma symptom severity and family functioning.

\section{Method}

\section{Participants}

A total of 247 participants provided consent to take part in the current research, a 
quantitative cross-sectional study using an online survey design. Only 143 started responding to the survey, and a final sample of $n=88$ fully completed the survey. Analyses comparing those caregivers with complete data $(n=88)$ with those with partial data not included in the final analyses $(n=55)$ is provided in the result section.

In order to meet inclusion criteria, participants were at least 18 years old, understood written English and were caregivers of a child or an adolescent with an asthma diagnosis residing in the UK. Following Hermanns and Mastel-Smith (2012), caregivers were defined as adults $(>18)$ who were providing unpaid support and were taking the main responsibility ( $>4$ hours daily) in caring for a child or adolescent that was under 18 years of age.

\section{Procedure}

Participants were recruited online between July and October 2017. The study was advertised on the Asthma Research UK bulletin, which is distributed on a monthly basis to the registered Research and Policy $(\mathrm{RaP})$ patient volunteers. The study was also advertised on UK asthma support groups on Twitter and Facebook. The advert included a link to a REDCap (Harris et al., 2009) online platform, a secure online data-collection system. The study received ethical approval by the University Research Ethics Committee (FHMREC).

\section{Instruments}

Mentalizing: The reflective functioning questionnaire (RFQ-8; Fonagy et al., 2016) was the self-report measure of parental mentalizing. It has two subscales: one regarding hypomentalizing, which assesses 'uncertainty about mental states' (RFQ-U), and one regarding hypermentalizing, which assesses 'certainty about mental states' (RFQ-C). In the RFQ-C subscale, average scores below the clinical cut off $(<2)$ reflected difficulties in mentalizing. In contrast, in the RFQ-U subscale, average scores above the clinical cut off $(>4)$ reflected poor mentalizing, with lower scores characterising greater ability to mentalize. This instrument has shown good test-retest reliability, with correlations ranging from $r=.75$ 
to .84 over a three-week period (Fonagy et al., 2016). The RFQ has also showed appropriate validity (Fonagy et al.,1998;2016) as established by the Adult Attachment Interview (AAI; George, Kaplan, \& Main, 1985). In the current study, the reliability analyses showed excellent internal consistency for the RFQ-C subscale $(\alpha=.83)$ and poor internal consistency for the RFQ-U subscale ( $\alpha=.52)$. As such, for the purpose of the regression analyses, the RFQ-C subscale was employed as a measure of mentalizing. Regression models using RFQ$\mathrm{U}$ are available upon request.

Family Functioning: The general functioning (GF) subscale of the Family Assessment Device (FAD; Epstein, Baldwin \& Bishop, 1983) was the measure of family functioning. This is a 12 -item likert scale, where average scores above 2.2 indicate family disruption. The GF has demonstrated high correlations with the overall FAD scores and can thus be used as an accurate measurement of family functioning on its own (Kabacoff, Miller, Bishop, Epstein, \& Keitner, 1990; Ridenour, Daley, \& Reich, 1999). This subscale has demonstrated adequate test-retest reliability $(r=.71-.77)$ (Akister \& Stevenson-Hinde, 1991; Bihun, Wamboldt, Gavin, \& Wamboldt, 2002; Epstein et al., 1983; Shek, 2001).The FAD showed excellent internal consistency $(\alpha=.91)$ in the current sample.

Anxiety: The Beck Anxiety Inventory (BAI; Beck, Epstein, Brown, \& Steer, 1988) is a 21-item self-report questionnaire which has been widely used in research and clinical settings. It has demonstrated adequate one-week test-retest reliability $(r=.75)$ (Beck et al., 1988). The internal consistency of the BAI was excellent in the current sample $(\alpha=.92)$.

Mood Disturbance: The 7 Up 7 Down Inventory (7U7D; Youngstrom, Murray, Johnson, \& Findling, 2013) was the self-report measure of mood symptoms. This scale was developed as a brief self-report questionnaire measuring depressive and hypomanic symptoms. Previous research has found mean clinical scores to be $<5.0$ in the $7 \mathrm{U}$ subscale and $<6.5$ in the $7 \mathrm{D}$ subscale.The 7U7D has demonstrated high correlations with the original 
General Behaviour Inventory scale ([GBI], Depue et al., 1981) and adequate construct validity (Youngstrom et al., 2013). The 7U7D showed excellent internal consistency $(\alpha=.80)$ for the 7Up and $(\alpha=.90)$ for the 7Down subscale in this sample.

Asthma Symptom Severity: The asthma symptom severity information was collected using an adapted set of questions from the questionnaire of Halterman et al. (2004). For the purpose of the analyses, a caregiver report of the number of asthma-free days over the last two weeks was employed as a measure of asthma symptom severity.

Clinical and Sociodemographics Information: An electronic questionnaire designed for the purpose of this study collected clinical and sociodemographic characteristics of the participants, such as gender, ethnicity, age, number of children in the household and income, among others.

\section{Statistical Analyses}

We conducted comparisons of main demographic variables between caregivers with complete and non-complete survey data. Following a previous research strategy employed to handle missing data (Eekhout et al., 2014; Siddiqui, 2015), only cases with less than $25 \%$ of items missing in the RFQ-8, 7U7D and FAD questionnaires were included in the final sample (10\% for the BAI questionnaire, Wetherell \& Areán, 1997).

We conducted descriptive analyses to explore and summarise the main demographic and clinical characteristics of the final sample. We employed correlation analyses to assess the relationships between clinical and demographic variables, plus sensitivity analyses to evaluate possible influential cases (multivariate outliers). Sequential linear regression analyses were employed as the aim of the study was to examine whether mentalizing was a greater contributor to the model than previously identified predictors. The regression models included anxiety, depression and hypomania as dependent variables and income, asthma symptom severity, family functioning and mentalizing as predictors. A priori sample size 
calculation indicated that in order to detect medium-to-large effect sizes in a multiple regression with four predictors at a probability of $\mathrm{p}=0.05$ and with a power of 0.80 , a minimum of 85 participants was required. All statistical analyses were conducted using IBM SPSS statistics software, version 22.

\section{Results}

Insert Table 1

The results did not show significant differences between participants with complete data and participants excluded due to missing data in any of the variables such as age, sex, ethnicity, income or education among others ( $p s>.05)$ (Table 1).

The mean age of caregivers was $36(\mathrm{SD}=7.13)$, of children $6(\mathrm{SD}=3.72), 97 \%$ were female and $94 \%$ described themselves as white. All participants were the mother or father of the child and $85 \%$ were married or cohabiting. Sixty-nine per cent of the caregivers reported a yearly income of $£ 26,000$ or more, and $57 \%$ had completed university education. For further socio-demographic and clinical information of the sample please refer to table 1. Insert Table 2

The correlations between clinical variables can be found in table 2. Most of the correlations were statistically significant, showing small and moderate effect sizes $(r=.01$ to .65 ) and running in the expected direction. For example, hypermentalizing was negatively correlated with depression $(r=-.49, p<.001)$, hypomania $(r=-.24, p<.05)$, anxiety $(r=-.44$, $\mathrm{p}<.01)$ and family functioning $(r=-.30, \mathrm{p}<.01)$, whereas hypomentalizing was positively associated with depression $(r=.50, p<.000)$ and anxiety $(r=0.28 p<.001)$. Given that low scores in the hypermentalizing subscale (RFQ-C) suggest poor mentalizing, and higher scores in the hypomentalizing subscale (RFQ-U) also suggest poor mentalizing (hypomentalizing), these correlations suggest that the poorer the mentalizing scores, the more likely the reporting of family functioning difficulties, anxiety and depressive and hypomanic symptoms. 


\section{Insert Table 3}

When exploring whether mentalizing was significantly associated with mood disturbance in comparison with the other predictors, mentaizing remained significantly associated with caregivers' depressive symptoms. In the most stringent model, the contribution of mentalizing to explaining depressive symptoms was $16 \%$ after introducing all of the predictors in the regression. Insert Table 4

In the case of hypomanic symptoms, mentalizing had a marginally significant contribution to the model after introducing all the predictors $(b=-.13, p=.050$; Table 4$)$. These results suggest that a unit increase in mentalizing was associated with a reduction in the selfreported depression and hypomanic symptom scores. Insert Table 5

In the last regression model regarding caregivers' anxiety, both mentalizing $(b=0.89$, $p<.001)$ and asthma symptom severity $(b=-.42, p<.05)$ were significantly associated with anxiety, although mentalizing explained $10 \%$ of the variance in anxiety, compared with children's asthma symptom severity, which only explained $3 \%$ of variance (Table 5 ). Similar to the regression models of depression and hypomania, increases in mentalizing units were associated with reductions in anxiety scores. Moreover, increases in the number of asthmafree days were also associated with reductions in anxiety. When using the other subscale of mentalizing (RFQ-U) as an independent variable, similar results were observed (data available under request from last author).

\section{Discussion}

This is the first study exploring mentalizing in caregivers of children with asthma. The findings show that poor mentalizing was significantly correlated with disrupted family functioning, anxiety and mood difficulties. Furthermore, mentalizing was the most important 
predictor of anxiety and depressive symptoms after introducing the competing variables of income, asthma symptom severity and family functioning. Results supported our hypotheses, in that those with poorer mentalizing scores were more likely to experience greater family disruption and greater symptoms of depression, anxiety and hypomania. This provides further support for the theoretical underpinnings of mentalizing theory, in that poor mentalizing capacity is associated with greater mental health difficulties (Bouchard et al., 2008).

Mentalizing was the most significant predictor in all the models, showing medium effect sizes for depression $(r=.40)$ and anxiety $(r=.36)$, and a small effect size for hypomania $(r=.20)$, indicating that higher levels of mentalizing were associated with a reduction in selfreported anxiety and mood difficulties. Mentalizing might be a buffering agent against caregivers' mental health difficulties, as previous literature has identified when looking at other client groups (Bateman \& Fonagy, 2013; Fonagy \& Bateman, 2016).

Asthma symptom severity also showed significant associations with anxiety in the final model, showing a small effect size ( $r=.17)$, and suggesting that mentalizing $(r=.36)$ was the most important factor in understanding caregivers' mental health difficulties. This is important given that recent studies have focused on asthma symptom severity as a significant predictor of poorer mental health outcomes amongst caregivers (Zaky, Fouda, Samir, \& Ahmed, 2016). In contrast, these results suggest that there are other factors, such as caregivers' mentalizing that require attention too. A mixed-method study suggested that losing control could be one of the dimensions associated with the burden of asthma (Guo, Gao, Guo, Wen, \& Zeng, 2015). It could be argued that mentalizing is intrinsically relevant to losing control, as it supports affect regulation (Fonagy et al., 2002).

Family functioning was not a significant predictor in any of the final models. This is particularly relevant given the extensive literature examining the significant association between disruptive family functioning and caregivers' mental health in both populations with 
asthma (Brown, Lambert, Hsu, \& Eckman, 1998; Jackson, 1992; Kung, 2003) and without asthma (Özkaya, Çetin, Uğurad, \& Samanci, 2010; Schreier \& Chen, 2010; Zhou et al., 2014). However, the previous studies did not include a mentalizing measure in their research. Given that the correlations in this study showed that positive mentalizing was associated with less disruptive family functioning, it is possible that mentalizing acts a mediating factor in the relationship between family functioning and caregivers' mental health difficulties. Thus, future longitudinal studies should aim to test this hypothesis through mediational analyses.

These results are promising, as they suggest that mentalizing could be an important factor in understanding caregivers' difficulties, irrespective of their income, family functioning and the asthma symptom severity of their children. Theoretically, this can be understood in the context of mentalizing being an essential component of affect regulation in emotionally charged situations (Migdley \& Vrouva, 2013), which are often present in the context of asthma caregiving duties (Bellin et al., 2013).

\section{Clinical Implications}

These results indicate that when caregivers' mentalizing capacity is compromised, the likelihood of experiencing mental health difficulties increases. Most interventions targeting caregivers of children with asthma have focused on problem-solving, psychoeducational and behavioural parenting programs or environmental triggers, among other aspects (Canino et al., 2008; Walders et al., 2006). We argued that interventions oriented towards mentalizing enhancement could be an additional option for this population. In fact, short-term parentalbased mentalization interventions have yielded promising results for both clinical (Suchman et al., 2010; 2017) and non-clinical populations of parents (Hertzmann et al., 2016). 


\section{Limitations and Future Research}

Although novel, this study presents some limitations. It employed an online cross-sectional design and only obtained self-reported data, which could reflect the effect of common method variance and other types of bias, such as memory bias when collecting information about asthma symptom severity (Schwarz, 2007). Although systematically validated measures of asthma severity were considered, shorter, less time consuming assessment procedures of asthma symptom severity were employed (i.e number of asthma free days in the last 14 days). This may have avoided greater attrition rates, but also may have compromised to some degree the validity when measuring asthma symptom severity. Furthermore, a similar limitation emerged with the asthma diagnosis as this was not verified by a physician report.

Mentalizing was measured using the short version of the reflective functioning questionnaire (RFQ-8). Ideally, this study would have measured parental mentalizing, rather than general mentalizing. Although general and parental mentalizing are strongly correlated, they are not exactly the same (Luyten et al., 2017). Future studies should aim to use the recently developed parental reflective functioning questionnaire (PRFQ) (Luyten, Mayes, Nijjssens, \& Fonagy, 2017), which was not published until the data collection for this study was already ongoing. By employing a parental mentalizing measure, future research could further explore the possible effect a caregiver's lack of mentalization might have on childhood asthma control.

Moreover, mentalizing proponents have described the concept as a capacity that occurs largely at a more implicit or automatic level (Fonagy et al., 2002), and thus it could be argued that it is hard for people to access it through self-report questionnaires. Future studies should include both self-report questionnaires and semi-structured interviews, such as the 
parent development interview (PDI) (Slade, Aber, Bresgi, Berger \& Kaplan, 2004), to allow assessment of more implicit/automatic mentalizing processes.

The sample was almost entirely comprised of mothers (97\%). The absence of fathers as informant caregives was consistent with asthma literature (Yamamoto \& Nagano, 2015). The fact that fathers were underrepresented in this convenience sample has multiple interpretations. For instance, the absence of father figures in the asthma caregiving literature may be a reflection of certain patterns of family functioning such as mothers acquiring the role of contacting healthcare providers and searching for asthma information in social media. This family dynamic might exert more stress over mothers, possibly influencing their mentalizing capacity, especially given that mothers are also primarily responsible for the caregiving of children with asthma. Thus, future research should take into account the possible role differences in caregiving and their impact in mentalizing ability.

Furthermore, over half of the sample had completed university education, the majority were white, and $69 \%$ of the families reported incomes of $£ 26,000$ or more, which is above the median income in the UK (Office for National Statistics, 2016). Given that asthma can pose significant financial burdens in the family unit (Zhou et al., 2014) and that socioeconomic status has been shown to predict worse anxiety, depression or quality of life outcomes in asthma caregivers (Annett, Bender, DuHamel, \& Lapidus, 2003; Celano et al., 2008; Erickson et al., 2003; Zhou et al., 2014), future studies should attempt to include a more diverse sample.

\section{Conclusions}

The findings of this study suggest that similar to the general population, mentalizing was an important factor in understanding caregivers' anxiety and mood difficulties. Although causal inferences could not be drawn due to the cross-sectional nature of the design, the results highlight the possible existence of an overlooked psychological construct that may 
influence caregivers' mental health. In doing so, the study paves the way for future research to further address the relationship between mentalizing and mental health difficulties amongst caregivers, as well as the effect that mentalizing deficits might have in the asthma outcomes of their children. 


\section{References}

Akister, J., \& Stevenson-Hinde, J. (1991). Identifying families at risk: Exploring the potential of the McMaster Family Assessment Device. Journal of Family Therapy, 13, 411-421. doi: 10.1046/j..1991.00437.x

Annett, R. D., Bender, B. G., DuHamel, T. T., \& Lapidus, J. (2003). Factors influencing parent reports on quality of life of children with asthma. Journal of Asthma, 40, 577-587.

Asthma UK (2016). The Asthma UK Data Portal. Retrieved from https://dev.asthma.org.uk/get-involved/campaigns/data-portal/ $16^{\text {th }}$ December 2016.

Bateman, A. W., \& Fonagy, P. (2013). Mentalization based treatment. Psychoanalytic Inquiry, 33(6), 595-613. Doi: 10.1080/07351690.2013.835170

Beck, A. T., Epstein, N., Brown, G., \& Steer, R. A. (1988). An inventory for measuring clinical anxiety: Psychometric properties. Journal of Consultant Clinical Psychology, 56(6), 893897. Doi: 10.1037/0022-006X.56.6.893

Bellin, M. H., Kub, J., Frick, K. D., Bollinger, M. E., Tsoukleris, M., Walker, J., Land, C., \& Butz, A. M. (2013). Stress and quality of life in caregivers of inner-city minority children with poorly controlled asthma. Journal of Pediatric Health Care: Official Publication of National Association of Pediatric Nurse Associates \& Practitioners, 27(2), 127-134. Doi: 10.1016/j.pedhc.2011.09.009

Bihun, J. T., Wamboldt, M. Z., Gavin, L. A., \& Wamboldt, F. S. (2002). Can the Family Assessment Device (FAD) be used with school aged children? Family Process, 41(4), 723-731. Doi: 10.1111/j.1545-5300.2002.00723.x

Bouchard, M. A.,Target, M., Lecours, S., Fonagy, P., Tremblay, L. M., Schachter, A., \& Stein, H. (2008). Mentalizing in adult attachment narratives: Reflective functioning, mental states, and affect elaborations compared. Psychoanalytic Psychology 25(1), 47-66. Doi: $10.1037 / 0736-9735.25 .1 .47$ 
British Lung Foundation (2016). The battle for breath - the impact of lung disease in the UK. Retrieved from https://www.blf.org.uk/policy/the-battle-for-breath-2016 22nd December 2016.

Brent, B. K., D. J. Holt, M. S. Keshavan, L. Seidman, J., \& Fonagy, P. (2014). Mentalizationbasedtreatment for psychosis: Linking an attachment-based model to the psychotherapy for impairedmental state understanding in people with psychotic disorders. Israel Journal of Psychiatry and Related Sciences, 51,17-24.

Brown, R. T., Lambert, R. G., Hsu, L., \& Eckman, J. R. (1998). Family functioning and social support in the adaptation of caregivers of children with sickle cell syndromes. Journal of Pediatric Psychology, 23, 377-388.

Byles, J., Byrne, C., Boyle, M. H., \& Offord, D. R. (1988). Ontario Child Health Study: reliability and validity of the general functioning subscale of the McMaster Family Assessment Device. Family Process, 27(1), 97-104.

Canino, G., Vila, D., Normand, S. L. T., Acosta-Pérez, E., Ramírez, R., García, P., \& Rand, C. (2008). Reducing asthma health disparities in Puerto Rican children: The effectiveness of a culturally tailored family intervention. Journal of Allergy and Clinical Immunology, 121, $665-670$.

Celano, M., Bakeman, R., Gaytan, O., Smith, C. O., Koci, A., \& Henderson, S. (2008). Caregiver depressive symptoms and observed family interaction in low-income children with persistent asthma. Family Process, 47, 7-20.

Cheezum, R. R., Parker, E. A., Sampson, N. R., Lewis, T. C., O'Toole, A., Patton, J., Robins, T. G., ... Keirns, C. C. (2013). Nightwatch: Sleep Disruption of Caregivers of Children With Asthma in Detroit. Journal of asthma \& allergy educators, 4(5), 217-225.

Claydon, E., Zerwas, S., Calinan, L., \& Smith, M. (2016). Parental reflective functioning among mothers with eating disorder symptomatology. Eating Behaviors, 23, 141-144. 
Doi: $10.1016 /$ j.eatbeh.2016.09.002

Depue, R. A., Slater, J.F., Wolfstetter-Kausch, H., Klein, D., Goplerud, E., \& Farr, D. (1981). A behavioral paradigm for identifying persons at risk for bipolar depressive disorder. Journal of Abnormal Psychology, 90, 381-437.

Easter, G., Sharpe, L., \& Hunt, C. J. (2015). Systematic review and meta-analysis of anxious and depressive symptoms in caregivers of children with asthma. Journal of Pediatric Psychology, 40(7), 623-632. Doi: 10.1093/jpepsy/jsv012.

Eekhout, I., de Vet, H. C. W., Twisk, J. W. R., Brand, J. P. L., de Boer, M. R., \& Heymans, M. W. (2014). Missing data in a multi-item instrument were best handled by multiple imputation at the item score level. Journal of Clinical Epidemiology, 67(3), 335-342.

Epstein, N. B., Baldwin, L. M., \& Bishop, D. S. (1983). The McMaster Family Assessment Device. Journal of Marital and Family Therapy, 9, 171-180.

Erickson, S. R., Munzenberger, P. J., Loewenstein, D. A., Rubert, M. P., Argüelles, S., Mitranin, V. B., \& Szapocznik, J. (2003). The effect of a family therapy and technology-based intervention on caregiver depression. The Gerontologist, 43, $521-531$.

Fonagy, P. (1989). On tolerating mental states: Theory of mind in borderline patients. Bulleting of the Anna Freud Centre, 12, 91-115.

Fonagy, P., \& Bateman, A. (2016). Adversity, attachment and mentalizing. Comprehensive Psychiatry, 64, 59-66. Doi: 10.1016/j.comppsych.2015.11.006

Fonagy, P., Gergely, G., Jurist, E., \& Target, M. (2002). Affect regulation, mentalization and the development of the self. New York, NY: Other Press.

Fonagy, P., Luyten, P., Moulton-Perkins, A., Lee, Y.-W., Warren, F., Howard, S.,...Lowych, B. (2016) Development and validation of a self-report measure of mentalizing: The Reflective Functioning Questionnaire. PLoS ONE, 11(7), 1-28. Doi: 
10.1371/journal.pone.0158678

Fonagy, P., Steele, M., Steele, H., Moran, G. S., \& Higgit, A. C. (1991). The capacity for understanding mental states. The reflective self in parent and child and its significance for security of attachment. Infant Mental Health Journal, 12(3), 201-218. Doi: 10.1002/10970355

Fonagy, P., Target, M., Steele, H. \& Steele, M. (1998). Reflective-functioning manual, Version 5, for application to Adult Attachment Interviews. Unpublished manuscript, University College London, London, UK.

George, C., Kaplan, N., \& Main, M. (1985). The Adult Attachment Interview. Unpublished manuscript, Department of Psychology, University of California at Berkeley, Berkeley, CA.

Global Initiative for Asthma (2017). Global Strategy for Asthma Management and Prevention. Retrieved December 2, 2017 from http://ginasthma.org/.

Guo, M., Gao, G., Guo, J., Wen, L., \& Zeng, L. (2015). Burden among caregivers for children with asthma: A mixed-method study in Guangzhou, China. International Journal of Nursing Sciences, 2(4), 394-401. Doi: 10.10.16/j.ijnss.2015.10.004

Gupta, R., Sheikh, A., Strachan, D. P., \& Anderson, H. R. (2004). Burden of allergic disease in the UK: Secondary analyses of national databases. Clinical \& Experimental Allergy, 34(4), 520-526. Doi: 10.1111/j.1365-2222.2004.1935.x

Halterman, J. S., Yoos, L., Conn, K., Callahan, P., Montes, G., Neely, T. L., \& Szilagyi, P. G. (2004). The impact of childhood asthma on parental quality of life. Journal of Asthma, 41(6), 645-653.

Harris, P. A., Taylor, R., Thielke, R., Payne, J., Gonzalez, N., \& Conde, J. G. (2009). Research electronic data capture (REDCap) - A metadata-driven methodology and workflow process for providing translational research informatics support. Journal of Biomedical 
Informatics, 42(2), 377-381. Doi: 10.1016/j.jbi.2008.08.010

Hermanns, M., \& Mastel-Smith, B. (2012). Caregiving: A qualitative concept analysis. The Qualitative Report, 17(38), 1-18.

Hertzmann, L., Target, M., Hewison, D., Casey, P., Fearon, P., \& Lassri, D. (2016). Mentalization-based therapy for parents in entrenched conflict: A random allocation feasibility study. Psychotherapy, 53(4), 388-401. Doi: 10.1037/pst0000092

Jackson, P. B. (1992). Specifying the buffering hypothesis: Support, strain and depression. Social Psychology Quarterly, 55, 363-378.

Kabacoff, R. I., Miller, I. W., Bishop, D. S., Epstein, N. B., \& Keitner, G. I. (1990). A psychometric study of the McMaster Family Assessment Device in psychiatric, medical and nonclinical samples. Journal of Family Psychology, 3, 431-439.

Kovacs, A. M., Teglas, E. \& Endress, A. D. (2010). The social sense: Susceptibility to others' beliefs in human infants and adults. Science 330, 1830-34. Doi:10.1126/science.1190792.

Kung, W. W. (2003). The illness, stigma, culture, or immigration? Burdens on Chinese American caregivers of patients with schizophrenia. Families in Society: The Journal of Contemporary Social Services, 84, 547-557.

Leiferman J. (2002). The Effect of Maternal Depressive Symptomatology on Maternal Behaviors Associated With Child Health. Health Education \& Behavior, 29, 596-607.

Lemma, A., Target, M. \& Fonagy, P. (2011). The development of a brief psychodynamic intervention(dynamic interpersonal therapy) and its application to depression: A pilot study. Psychiatry (Edgmont) 74, 41-48. Doi:10.1521/psyc.2011.74.1.41.

Luyten, P., Fonagy, P., Lowyck, B., \& Vermote, R. (2012). Assessment of mentalization. In Bateman, A. \& Fonagy, P. (2012). Handbook of mentalizing in mental health practice, $\left(1^{\text {st }}\right.$ 
ed. Pp 43-65. Washington, DC: American Psychiatric Association.

Luyten, P., Mayes, L. C., Nijssens, L., \& Fonagy, P. (2017). The parental reflective functioning questionnaire: Development and preliminary validation. PLOS ONE, 12(5), e0176218. Retrieved from http://doi.org/10.1371/journal.pone.0176218

Mallol, J., Crane, J., von Mutius, E., Odhiambo, J., Keil, U., \& Stewart, A.; ISAAC Phase Three Study Group (2013). The International Study of Asthma and Allergies in Childhood (ISAAC) Phase Three: A global synthesis. Allergologia et Immunopathologia, 4 (2), $73-$ 85. Doi: 10.1016/j.aller.2012.03.001

Meins, E., Fernyhough, C., Fradley, E., \& Tuckey, M. (2001). Rethinking maternal sensitivity: Mothers' comments on infants' mental processes predict security of attachment at 12 months. Journal of Psychology and Psychiatry, 42(5), 637-648. Doi: 10.1111/14697610.00759

Migdley, N., \& Vrouva, I. (2013). Minding the child: Mentalization-based interventions with children, young people and their families (1st ed.). New York: Routledge.

Mukherjee, M., Gupta, R., Farr, A., Heaven, M., Stoddart, A., Bright I, N.,...Sheikh, A., on behalf of the Burden and True Cost of Asthma in the UK Research Team (2014) Estimating the incidence, prevalence and true cost of asthma in the UK: Secondary analysis of national stand-alone and linked databases in England, Northern Ireland, Scotland and Wales - a study protocol. BMJ Open, 4(11), e006647. Doi: 10.1136/bmjopen-2014-006647

Nunes, C., Pereira, A. M., \& Morais-Almeida, M. (2017). Asthma costs and social impact. Asthma Research and Practice, 3, 1. Retrieved from http://doi.org/10.1186/s40733-016-0029-3

Office for National Statistics (2016). Household disposal income and inequality in the UK: Financial year ending 2016. Retrieved March 18, 2018 from https://www.ons.gov.uk/peoplepopulationandcommunity/personalandhouseholdfinances/ 
incomeandwealth/bulletins/householddisposableincomeandinequality/financialyearendin g2016.

Özkaya, E., Çetin, M., Uğurad, Z., \& Samanci, N. (2010). Evaluation of family functioning and anxiety-depression parameters in mothers of children with asthma. Allergol Immunopathology, 38(1), 25-30. Doi: 10.106/j.aller.2009.06.004

Reyes, M., Perzanowski, M. S., Whyatt, R. M., Kelvin, E. A., Rundle, A. G., Diaz, D. M.,...Miller, R. L. (2011). Relationship between maternal demoralization, wheeze and inmunoglobin E among inner-city children. Annals of Allergy, Asthma \& Immunology, $107(1), 42-49$.

Ridenour, T. A., Daley, J., \& Reich, W. (1999). Factor anlyses of the family assessment device. Family Process, 38, 497-510.

Sadler, L. S., Slade, A., Close, N., Webb, D. L., Simpson, T., Fennie, K., \& Mayes, L. C. (2013). Minding the baby: Enhancing effectiveness to improve early healthy and relationship outcomes in an interdisciplinary home-visiting program. Infant Mental Health Journal, 35(4). Doi: 10.1002/imhj.21406

Sato, A. F., Kopel, S. J., McQuaid, E. L., Seifer, R., Esteban, C., Coutinho, M. T.,....KoinisMitchell, D. (2013). The home environment and family asthma management among ethnically diverse youth with asthma. Family, Systems \& Health, 31, 156-170. Doi: $10.1037 / \mathrm{a} 0032462$

Schreier, H., \& Chen, E. (2010). Longitudinal relationships between family routines and biological profiles among youth with asthma. Health Psychology, 29, 82-90.

Schwarz, N. (2007). Retrospective and concurrent self-reports: The rationale for real-time data capture. In A. Stone, S. S. Shiffman, A. Atienza, \& L. Nebelling (Eds)., Handbook of research methods for studying daily life (pp. 11-26). New York: Oxford University Press.

Shalowitz, M. U., Mijanovich, T., Berry, C. A., Clark-Kauffman, E., Quinn, K.. A.\& Perez E. 
L. (2006). Context matters: a community-based study of maternal mental health, life stressors, social support, and children's asthma. Pediatrics, 117, 940-948.

Shek, D. T. L. (2001). The general functioning scale of the Family Assessment Device: Does it work with Chinese adolescents? Journal of Clinical Psychology, 57(12), 1503-16.

Siddiqui, O. I. (2015). Methods for computing missing item reponse in psychometric scale construction. American Journal of Biostatics, 5(1), 1-6. Doi: 10.3844/amjbsp.2015.1.6

Slade, A., Aber, J. L., Bresgi, I., Berger, B., \& Kaplan, C. A. (2004). The Parent Development Interview - Revised. New York: The City University of New York.

Suchman, N. E., DeCoste, C., Castiglioni, N., McMahon, T. J., Rounsaville, B., \& Mayes, L. (2010). The Mothers and Toddlers Program, an attachment-based parenting intervention for substance using women: Post-treatment results from a randomized clinical pilot. Attachment \& Human Development, 12(5), 483-504. Doi: $10.1080 / 14616734.2010 .501983$

Suchman, N. E., DeCoste, C. L., McMahon, T. J., Dalton, R., Mayes L. C., \& Borelli, J. (2017). Mothering from the inside out: Results of a second randomized clinical trial testing a mentalization-based intervention for mothers in addiction treatment. Development and Psychopathology, 29, 617-636. Doi: 10.1017/S0954579417000220

Walders, N., Kercsmar, C., Schluchter, M., Redline, S., Kirchner, L., \& Drotar, D. (2006). An interdisciplinary intervention for undertreated paediatric asthma. Chest, 129, 292-299.

Wetherell, J. L., \& Areán, P. A. (1997). Psychometric evaluation of the Beck Anxiety Inventory with older medical patients. Psychological Assessment,9(2), 136-144. Doi: $10.1037 / 1040-3590.9 \cdot 2.136$

Wood, B. L., Brown, S. E., Lehman, H. K., Khan, D. A., Jung Lee, M., \& Miller, B. D. (2018). The effects of caregiver depression on childhood asthma: Pathways and mechanisms. Annals of Allergy, Asthma Immunology. Doi:10.1016/j.anai.2018.06.031 
Wood, P. R., Smith, L. A., Romero, D., Bradshaw, P., Wise, P. H., \& Chavkin, W. (2002). Relationships between welfare status, health insurance status, and health and medical care among children with asthma. American Journal of Public Health, 92, 1446-1452.

Yamamoto, N. \& Nagano, J. (2015). Parental stress and the onset and course of childhood asthma. BioPsychoSocial Medicine, 9(7), 1-8. Doi: 10.1186/s13030-015-0034-4.

Youngstrom, E. A., Murray, G., Johnson, S. L., \& Findling, R. L. (2013). The 7 Up 7 Down Inventory: A 14-item measure of manic and depressive tendencies carved from the General Behavior Inventory. Psychological Assessment, 25(4), 1377-1383. Doi: $10.1037 / \mathrm{a} 0033975$

Youngstrom, E.A., \& Perez Algorta, G. (2015). Features and course of bipolar disorder. In Hammen, C., \& Gotlib, I. (Eds.), Handbook of Depression, $3^{\text {rd }}$ Ed. New York, NY: Guilford Press.

Zaky, E., Fouda, E., Samir, E., \& Ahmed, F. (2016). Pediatric asthma biomarkers in relation to mental disorders of asthmatic children and their caregivers. European Psychiatry, 33, 385-386. Doi: 10.1016/j.eurpsy.2016.01.1386

Zhou, T., Yi, C., Zhang, X., \& Wang, Y. (2014). Factors impacting the mental health of the caregivers of children with asthma in China: Effects of socioeconomic status, symptoms control, proneness to shame and family functioning. Family Process, 53(4), 717-730. Doi: 10.1111/famp.12099 


\section{Tables}

Table 1.

Participant demographics and clinical characteristics

\begin{tabular}{|c|c|c|c|}
\hline$\underline{\text { Caregivers }}$ & Excluded Cases $(\mathrm{N}=55)$ & Included Cases $(\mathrm{N}=88)$ & $x^{2} / t$ \\
\hline Age, Mean (SD) & $35.19(6.24)^{\mathrm{a}}$ & $36.68(7.13)$ & $t=-.1 .18$ \\
\hline Sex female, $\mathrm{n}(\%)$ & $53(98)^{b}$ & $85(97)$ & $x^{2}=.29$ \\
\hline Ethnicity White, n (\%) & $46(85)^{\mathrm{b}}$ & $83(94)$ & $x^{2}=3.35$ \\
\hline Relation to child (mother or father), $\mathrm{n}(\%)$ & $51(94)^{\mathrm{b}}$ & $87(100)$ & $x^{2}=4.93$ \\
\hline Income, $\mathrm{n}(\%)^{\mathrm{c}}$ & & & $x^{2}=7.40$ \\
\hline 6,000 to $>26,000$ & $18(34)$ & $27(30)$ & \\
\hline 26,000 to $>48,000$ & $17(32)$ & $30(34)$ & \\
\hline 48,000 and above & $18(34)$ & $21(35)$ & \\
\hline Qualifications, University Studies, n (\%) & $26(48)^{\mathrm{c}}$ & $50(57)$ & $x^{2}=5.11$ \\
\hline Marital Status, Married or cohabiting, n (\%) & $34(81)^{\mathrm{d}}$ & $64(84)$ & $x^{2}=.20$ \\
\hline \multicolumn{4}{|l|}{$\underline{\text { Clinical Variables }}$} \\
\hline Hypomentalizing (RFQ-U), Mean (SD) & & $2.48(2.54)$ & \\
\hline Hypermentalizing (RFQ-C), Mean (SD) & & $7.37(5.13)$ & \\
\hline Anxiety scores (BAI), Mean (SD) & & $36.62(11.50)$ & \\
\hline Family Functioning Scores (FD), Mean & & $23.09(8.15)$ & \\
\hline \multicolumn{4}{|l|}{ (SD) } \\
\hline Hypomania Scores (7Up), Mean (SD) & & $3.46(3.27)$ & \\
\hline Depression Scores (7Down), Mean (SD) & & $6.53(5.17)$ & \\
\hline Children & Excluded Cases $(\mathrm{N}=55)$ & $\underline{\text { Included Cases }}(\mathrm{N}=88)$ & $x^{2} / t$ \\
\hline Age, Mean (SD) & $5.94(3.67)^{\mathrm{e}}$ & $6.53(3.72)$ & $t=-.89$ \\
\hline Sex female, $\mathrm{n}(\%)$ & $19(36)^{\mathrm{c}}$ & $39(45)$ & $x^{2}=1.09$ \\
\hline Ethnicity White, n (\%) & $44(80)$ & $80(91)$ & $x^{2}=3.49$ \\
\hline \multicolumn{4}{|l|}{ Asthma Symptom Severity } \\
\hline $\mathrm{N}^{\mathrm{o}}$ days with asthma daytime symptoms, $\mathrm{M}$ & $5.93(4.00)^{\mathrm{b}}$ & $5.92(3.93)$ & $t=.00$ \\
\hline \multicolumn{4}{|l|}{ (SD) } \\
\hline $\mathrm{N}^{\mathrm{o}}$ days with with asthma night-time & $5.76(4.03)$ & $5.42(4.13)$ & $t=.48$ \\
\hline \multicolumn{4}{|l|}{ symptoms, M (SD) } \\
\hline $\mathrm{N}^{\circ}$ of asthma free days, $\mathrm{M}(\mathrm{SD})$ & $6.20(5.26)^{\mathrm{c}}$ & $6.72(5.09)$ & $t=-.58$ \\
\hline $\mathrm{N}^{\circ}$ days Use of rescue inhaler, $\mathrm{M}(\mathrm{SD})$ & $5.51(4.42)$ & $5.68(4.41)$ & $t=-.22$ \\
\hline
\end{tabular}

Note ${ }^{*} \mathrm{p}<0.05,{ }^{*} \mathrm{p}<0.01 * * * \mathrm{p}<0.001, x^{2}=$ Chi Square, $t=$ Student's t-test, ${ }^{\mathrm{a}} \mathrm{n}=47,{ }^{\mathrm{b}} \mathrm{n}=54,{ }^{\mathrm{c}} \mathrm{n}=53,{ }^{\mathrm{d}} \mathrm{n}=42,{ }^{\mathrm{e}} \mathrm{n}=50$ 
Table 2 .

Pearson's $r$ correlations between clinical variables

\begin{tabular}{|c|c|c|c|c|c|c|c|}
\hline $\mathrm{N}=88$ & Hypomania & Depression & Anxiety & Family Functioning & $\begin{array}{l}\text { Hypomentalizing } \\
\text { (Hypermentalizing) }\end{array}$ & Asthma Free days & Rescue Inhaler ${ }^{\mathrm{a}}$ \\
\hline $7 \mathrm{Up}, \mathrm{r}$ & & $.33 * * *$ & $.49 * * *$ & .09 & $.20(-.24 *)$ & -.09 & .14 \\
\hline 7Down, $r$ & $.33 * * *$ & & $.47 * * *$ & $.30 * *$ & $.50 * * *(-.49 * * *)$ & -.02 & .04 \\
\hline BAI, r & $.49^{* * *}$ & $.46^{* * *}$ & & .18 & $.28 * *(-.44 * *)$ & $-.22 *$ & $.22 *$ \\
\hline $\mathrm{FAD}, \mathrm{r}$ & .09 & $.30 * *$ & .18 & & $.19\left(-.30^{* *}\right)$ & .05 & .01 \\
\hline RFQ-U (RFQ-C) & $.20(-.24 *)$ & $.50 * * *(-.49 * * *)$ & $.28 * *(-.44 * * *)$ & $.19\left(-.30^{* *}\right)$ & $-.61^{* * *}$ & $-.09(0.08)$ & $.15(-.10)$ \\
\hline Asthma Free & -.09 & -.02 & $-.22 *$ & .05 & $-.09(.08)$ & & $-.65 * *$ \\
\hline \multicolumn{8}{|l|}{ Days } \\
\hline Rescue Inhaler & .14 & .04 & $.22 *$ & .01 & $.15(-.10)$ & $-.65 * *$ & \\
\hline Use & & & & & & & \\
\hline
\end{tabular}

Note $={ }^{*} \mathrm{p}<.05,{ }^{*} \mathrm{p}<.01 * * * \mathrm{p}<.001,{ }^{\mathrm{a}}$ Rescue Inhaler $=$ Refers to the number of days where rescue inhaler was needed in the last two weeks 
Table 3

Regression model predicting depressive symptoms (7D)

\begin{tabular}{|c|c|c|c|c|c|c|c|}
\hline \multirow{2}{*}{$\begin{array}{l}\underline{\text { Variable }} \\
\text { Depression }(\mathrm{N}=88)\end{array}$} & \multirow[t]{2}{*}{ Step 1} & \multirow[t]{2}{*}{ Step 2} & \multirow[t]{2}{*}{ Step 3} & \multirow[t]{2}{*}{ Step 4} & \multicolumn{2}{|c|}{$95 \% \mathrm{CI}$} & \multirow[t]{2}{*}{ Semipartial Correlation } \\
\hline & & & & & Upper & Lower & \\
\hline Constant $^{\mathrm{a}}$ & $6.56 * * *$ & $6.68 * * *$ & 2.74 & $7.54 * * *$ & 11.51 & 3.57 & \\
\hline Income $^{\mathrm{a}}$ & -.01 & .00 & -.29 & -0.17 & .69 & -1.05 & .00 \\
\hline Asthma Symptom Severity ${ }^{\mathrm{a}}$ & & -.02 & -.03 & .01 & .20 & -.18 & .00 \\
\hline Family Functioning ${ }^{\mathrm{a}}$ & & & $.20 * *$ & .11 & .24 & -.15 & .02 \\
\hline Hypermentalizing (RFQ-C) ${ }^{\mathrm{a}}$ & & & & $-.44 * * *$ & -.24 & -.64 & .16 \\
\hline $\mathrm{R}^{2}$ & .00 & .00 & $.09 * *$ & $.27 * * *$ & & & \\
\hline $\mathrm{F}$ & .01 & .02 & $3.01 *$ & $7.71 * * *$ & & & \\
\hline$\Delta \mathrm{R}^{2}$ & .00 & .00 & $.09 *$ & $.17 * * *$ & & & \\
\hline$\Delta \mathrm{F}$ & .01 & .04 & $9.00 *$ & $19.79 * * *$ & & & \\
\hline
\end{tabular}

Note $=* \mathrm{p}<.05,{ }^{* *} \mathrm{p}<.01 * * * \mathrm{p}<.001,{ }^{\mathrm{a}}$ All values are unstandardized Beta coefficients 
Table 4

Regression model predicting hypomanic symptoms (7U)

\begin{tabular}{|c|c|c|c|c|c|c|c|}
\hline Variable & Step 1 & Step 2 & Step 3 & Step 4 & \multicolumn{2}{|c|}{$95 \%$ CI } & Semipartial Correlation $^{2}$ \\
\hline Mania $(\mathrm{N}=88)$ & & & & & Upper & Lower & \\
\hline Constant $^{\mathrm{a}}$ & $4.66^{* * * *}$ & $4.88^{* * * *}$ & $3.77^{* * *}$ & $5.27 * * *$ & 8.06 & 2.48 & \\
\hline Income $^{a}$ & -.52 & -.49 & -.57 & -.54 & .07 & -1.15 & .03 \\
\hline Asthma Severity & & -.04 & -.04 & -.03 & .10 & -.16 & .00 \\
\hline Family Functioning ${ }^{a}$ & & & .05 & .02 & .11 & -.06 & .00 \\
\hline Hypermentalizing (RFQ-C) & & & & $-.13 *$ & .00 & -.27 & .04 \\
\hline $\mathrm{R}^{2}$ & .03 & .03 & .05 & $.09 *$ & & & \\
\hline $\mathrm{F}$ & 2.97 & 1.66 & 1.69 & 2.28 & & & \\
\hline$\Delta \mathrm{R}^{2}$ & .03 & .00 & .01 & $.04^{*}$ & & & \\
\hline$\Delta \mathrm{F}$ & 2.97 & .38 & 1.70 & $3.88^{*}$ & & & \\
\hline
\end{tabular}

Note $=* \mathrm{p}<.05, * * \mathrm{p}<.01 * * * \mathrm{p}<.001,{ }^{\text {a }}$ All values are unstandardized Beta coefficients 
Table 5

Regression model predicting anxiety (BAI)

\begin{tabular}{|c|c|c|c|c|c|c|c|}
\hline$\underline{\underline{V} \text { ariable }}$ & Step 1 & Step 2 & Step 3 & Step 4 & \multicolumn{2}{|c|}{$95 \% \mathrm{CI}$} & Semipartial Correlation ${ }^{2}$ \\
\hline Anxiety $(\mathrm{N}=88)$ & & & & & Upper & Lower & \\
\hline Constant $^{\mathrm{a}}$ & $37.84 * * *$ & $40.42 * * *$ & $34.53 * * *$ & $44.17 * * *$ & 53.19 & 35.15 & \\
\hline Income $^{a}$ & -.53 & -.18 & -.63 & -.40 & 1.58 & -2.38 & .00 \\
\hline Asthma Severity ${ }^{\mathrm{a}}$ & & $-.50^{*}$ & $-.51 * *$ & $-.42 *$ & .01 & -.86 & .03 \\
\hline Family Functioning ${ }^{a}$ & & & $.30^{*}$ & .12 & .41 & -.16 & .00 \\
\hline Hypermentalizing (RFQ-C) ${ }^{\mathrm{a}}$ & & & & $-.89 * * *$ & -.44 & -1.34 & 0.13 \\
\hline $\mathrm{R}^{2}$ & .00 & $.05^{*}$ & $.09 *$ & $.24 * * *$ & & & \\
\hline $\mathrm{F}$ & .24 & 2.28 & $2.93^{*}$ & $6.45^{* * *}$ & & & \\
\hline$\Delta \mathrm{R}^{2}$ & .00 & $.04 *$ & $.04 *$ & $.14 * * *$ & & & \\
\hline$\Delta \mathrm{F}$ & .24 & $4.30^{*}$ & $4.07 *$ & $15.47 * * *$ & & & \\
\hline
\end{tabular}

Note $=* \mathrm{p}<.05, * * \mathrm{p}<.01 * * * \mathrm{p}<.001,{ }^{\mathrm{a}}$ All values are unstandardized Beta coefficients 